\title{
Determinants of Blood Uric Acid Levels in a Dyslipidemic Arab Population
}

\author{
Ahoud F. Al-Meshaweh ${ }^{\mathrm{a}}$ Yaqoub Jafar ${ }^{\mathrm{b}}$ Mohammad Asem ${ }^{\mathrm{a}}$ \\ Abayomi O. Akanjic \\ ${ }^{a}$ Kuwait University Faculty of Medicine, ${ }^{b}$ Department of Surgery, Mubarak Al-Kabeer Hospital, and \\ 'Department of Pathology, Kuwait University Faculty of Medicine, Jabriya, Kuwait
}

\section{Key Words}

Urate $\cdot$ Metabolic syndrome $\cdot$ Dyslipidemia $\cdot$ Arabs .

Insulin resistance $\cdot$ Coronary artery disease .

Hydroxymethylglutaryl coenzyme A reductase inhibitor

\begin{abstract}
Objectives: The objective of this study was to explore the relationships between circulating uric acid and lipid levels and components of the metabolic syndrome (MetS) in Arab dyslipidemic patients, a group already at high coronary artery disease risk. Subjects and Methods: The medical records of 1,229 subjects (632 men, 597 women) referred for treatment of dyslipidemia and followed up for at least 12 months were reviewed. Serum levels of uric acid and lipids (total cholesterol, triglycerides, low-density lipoprotein, high-density lipoprotein) and other variables in the National Cholesterol Education Program ATP III criteria definition of MetS were assessed at initial presentation and every 46 months, under specific lipid-lowering treatment (statins and/or fibrates), in each of the subjects. Their respective associations were explored by appropriate logistic regression techniques with control for confounding risk factors, including age, gender and body mass index. Results: 306 subjects (24.9\%) of the study population were hyperuricemic; they were more likely to be men, obese and diabetic. Also the se-
\end{abstract}

rum uric acid level (mean \pm SD) was greater in men with MetS compared with men without (377.0 \pm 98.0 vs. $361.6 \pm$ $83.1 \mu \mathrm{mol} / \mathrm{l}, \mathrm{p}<0.05)$, an observation not reproduced in women. Uric acid levels had significant associations with the presence of fasting hyperglycemia, hypertension and large waist circumference (WC) in men, but only with large WC in women. With statin treatment, uric acid levels decreased by $10 \%$ within 1 year of treatment; with fibrates, uric acid levels remained unchanged or slightly increased. Conclusion: The data showed that hyperuricemia is common in dyslipidemic patients in Kuwait, where its important determinants are male sex, obesity, diabetes and statin treatment.

Copyright $\odot 2011$ S. Karger AG, Basel

\section{Introduction}

The recent interest in hyperuricemia stems from its high prevalence and increasing recognition as a risk factor for coronary artery disease (CAD). The worldwide prevalence of hyperuricemia is high, with reported rates of $35.1 \%$ (men) and $8.7 \%$ (women) in the Seychelles [1], $10.6 \%$ in Thailand [2], $7.2 \%$ (men) and $0.04 \%$ (women) in England and Scotland [3], 11.2\% in the USA [4] and 8.4\% in Saudi Arabia [5]. The putative associations of hyperuricemia in these populations include age, gender, smok-

\section{KARGER \\ Fax +41613061234 \\ E-Mail karger@karger.ch}

www.karger.com
(C) 2011 S. Karger AG, Basel

1011-7571/12/0213-0209\$38.00/0

Accessible online at:

www.karger.com/mpp
Yaqoub Jafar

Department of Surgery, Mubarak Al-Kabeer Hospital

PO Box 24923

Safat 13110 (Kuwait)

Tel. +965 5055 5677, E-Mail yaqoub.ashkanani@ hotmail.com 
ing, alcohol consumption and lifestyle, which in themselves are also risk factors for CAD and stroke [6], among other variables, also seen at high frequencies in individuals with hyperuricemia. There is some suggestion therefore that uric acid may not be independently related to $\mathrm{CAD}$ risk but is merely epiphenomenal.

An accepted risk factor for CAD is the presence of the metabolic syndrome (MetS). MetS is highly prevalent worldwide being seen in $9.1 \%$ of female Kuwaiti adolescents [7], $13-31 \%$ of Turks [8] and up to $21.8 \%$ of the adult US population [9]. In at least one study from China, a link between MetS and uric acid levels has been suggested [10], an observation worthy of further investigation. Furthermore, not all dyslipidemic disorders (especially those associated with a predominant increase in low-density lipoprotein, LDL, levels) are components of MetS, and it is of interest to see how uric acid levels relate to these nonMetS lipid components, which are typically measured routinely in lipid clinic patients. Indeed, some studies have suggested that serum uric acid fell by about $4-8 \%$ in dyslipidemic patients on specific lipid-lowering medications $[11,12]$.

Atherosclerotic vascular diseases (especially CAD and stroke) are common in Arab countries, undoubtedly due to the high prevalence of dyslipidemia and diabetes singly or jointly as in MetS $[13,14]$. It is essential to investigate how all these latter factors interact with the high prevalence of hyperuricemia in individuals who are already at high risk for CAD. Most of the reported studies on these interactions have been from Caucasian and East Asian populations [10-12], with none from Gulf Arab countries, which are currently undergoing rapid economic and social transformation. This study therefore aimed to assess: prevalence of hyperuricemia in dyslipidemic Arab patients on follow-up in a lipid clinic; associations of uric acid levels with presence of dyslipidemia and/or MetS and its components, and changes in uric acid levels with 1 -year standard treatment for dyslipidemia.

\section{Subjects and Methods}

\section{Study Design}

The study design was retrospective and cross-sectional with at least a 1-year longitudinal component. The database of the Lipid Clinic, Mubarak Al-Kabeer Hospital, Kuwait, was used. This Lipid Clinic is the only formal service for treating dyslipidemic patients in the country, and receives referrals from all the other public and private hospitals in the country. We reviewed the records of 1,229 dyslipidemic patients, comprising 632 men and 597 women aged (mean \pm SD) $48.7 \pm 10.5$ years. These were serially presenting subjects referred to the Lipid Clinic. The patients reviewed were those who had complete clinic follow-up data for at least 12 months and had visited regularly at about 4- to 6-month intervals. All those subjects with incomplete data were excluded, as were those under specific treatment for hyperuricemia. There were only 5 patients already on allopurinol and they were not included in the study. The study was approved by the local Research Ethics Committee of the Faculty of Medicine, Kuwait University.

\section{Anthropometric and Laboratory Measurements}

For each patient, at first visit (baseline) and subsequent followup visits at 4- to 6-month intervals, overnight fasting blood samples were collected for measurements of serum levels of lipids and lipoproteins [triglycerides (TG), total cholesterol (TC), high-density lipoprotein cholesterol (HDL-C)], apolipoproteins A and B, glucose, uric acid and standard liver and renal function indices, as well as amylase and creatine kinase. The LDL-C levels were calculated using the Friedewald formula [15], applied in all cases with serum TG $<4.50 \mathrm{mmol} / \mathrm{l}$. These laboratory measurements were made using AutoAnalyzer (Beckman-Coulter DxC, Fullerton, Calif., USA) at the Mubarak Al-Kabeer Hospital Clinical Chemistry Laboratory, with robust quality control procedures. The routine enzymatic methods used were: glucose (hexokinase), TC and HDL-C (cholesterol esterase), TG (lipase) and uric acid (uricase).

In addition, anthropometric indices of height, weight and waist (WC) and hip circumferences were measured - WC at the umbilicus, midway between the lower rib cage and the iliac crest, and hip circumference at the greatest gluteal protuberance. The body mass index (BMI) was calculated as weight $(\mathrm{kg})$ divided by height squared $\left(\mathrm{m}^{2}\right)$; obesity was defined as BMI $\geq 30 \mathrm{~kg} / \mathrm{m}^{2}[16]$. Similarly, the presence of MetS was diagnosed according to the National Cholesterol Education Program ATP III criteria [16] requiring at least 3 of the following 5 components: abdominal obesity (WC $>102 \mathrm{~cm}$ in men; $>88 \mathrm{~cm}$ in women); low HDL-C $(<1.00 \mathrm{mmol} / \mathrm{l}$ in men, $<1.29 \mathrm{mmol} / \mathrm{l}$ in women); elevated TG $(\geq 1.69 \mathrm{mmol} / \mathrm{l}$ ); fasting hyperglycemia (glucose $\geq 6.1 \mathrm{mmol} / \mathrm{l}$ ) and hypertension (blood pressure, BP, $\geq 130 / 85 \mathrm{~mm} \mathrm{Hg}$ ). Subjects were classified as hyperuricemic with serum uric acid levels $\geq 416 \mu \mathrm{mol} / \mathrm{l}$ for men and $\geq 358 \mu \mathrm{mol} / \mathrm{l}$ for women [16].

\section{Statistical Analysis}

Data management and analyses were done using the Statistical Package for Social Sciences version 17.0 for Windows. The respective variables were summarized using median, range and proportion where appropriate. Age, a continuous variable, was divided into two categories according to National Cholesterol Education Program ATP III criteria for the risk of ischemic heart disease [16]. Frequency distributions were used for descriptive analysis. The associations between the categorical variables were tested for significance with the $\chi^{2}$ test. The nonparametric Mann-Whitney $\mathrm{U}$ test was applied to comparing TG values, while data for the other variables, including TC, HDL-C, LDL-C, glucose and uric acid were compared using 2 -sample $t$ tests. A comparison of parameters among 4 groups according to the number of risk factors for MetS was performed by analysis of variance between groups and the Scheffé test, while the changes in uric acid and lipid parameters in all treatment groups were evaluated by repeated-measures analysis of variance and Bonferroni adjustment for multiple comparisons. A p value of $<0.05$ was considered significant. 
Table 1. Demographic, anthropometric and biochemical baseline characteristics of the subjects according to baseline serum uric acid levels

\begin{tabular}{|c|c|c|c|c|}
\hline & All & Hyperuricemia & Normouricemia & $\mathrm{p}$ \\
\hline Number of patients & 1,229 & 294 & 935 & \\
\hline Males/females & $630 / 599$ & $172 / 122$ & $458 / 477$ & \\
\hline Age, years & $48.7 \pm 10.5$ & $47.1 \pm 9.8$ & $46.8 \pm 10.6$ & 0.395 \\
\hline Weight, kg & $78.1 \pm 16.3$ & $83 \pm 16.1$ & $78.1 \pm 15.6$ & $<0.001$ \\
\hline BMI, kg/m² & $30.2 \pm 5.6$ & $31.4 \pm 5.6$ & $30.1 \pm 5.4$ & 0.001 \\
\hline $\mathrm{WC}, \mathrm{cm}$ & $99.3 \pm 12.2$ & $102.9 \pm 11.3$ & $98.8 \pm 11.9$ & $<0.001$ \\
\hline $\mathrm{TC}, \mathrm{mmol} / \mathrm{l}$ & $7.3(0.78-34)$ & $7.3(2.13-17)$ & $7.3(0.78-34)$ & 0.178 \\
\hline LDL-C, mmol/l & $5.2(1.2-33.3)$ & $5.3(1.2-14.4)$ & $5.2(1.3-33.3)$ & 0.773 \\
\hline HDL-C, mmol/l & $1.10 \pm 0.35$ & $1.11 \pm 0.39$ & $1.16 \pm 0.33$ & 0.572 \\
\hline $\mathrm{TG}, \mathrm{mmol} / \mathrm{l}$ & $2.1(0.1-26.0)$ & $2.1(0.5-17.6)$ & $2.0(0.1-26.0)$ & 0.024 \\
\hline Uric acid, $\mu \mathrm{mol} / \mathrm{l}$ & $328.6 \pm 85.0$ & $441.0 \pm 64.4$ & $297.9 \pm 60.6$ & $<0.001$ \\
\hline Glucose, mmol/l & $5.9(3.5-26.6)$ & $5.8(3.5-26.6)$ & $5.8(4.0-25.7)$ & 0.275 \\
\hline Systolic BP, mm Hg & $135 \pm 18$ & $136 \pm 18$ & $135 \pm 18$ & 0.186 \\
\hline Diastolic BP, mm Hg & $85 \pm 10$ & $87 \pm 12$ & $85 \pm 10$ & 0.027 \\
\hline
\end{tabular}

Results are expressed as means \pm SD or medians with ranges in parentheses. $p$ values are given for differences between hyperuricemic and normouricemic groups.

\section{Results}

The demographic, anthropometric and biochemical characteristics of all the subjects considered as a whole and when subdivided into hyperuricemic and normouricemic groups are given in table 1 . There were a total of 1,229 subjects with complete data - $630(51.4 \%)$ men and $599(48.6 \%)$ women, with a mean ( \pm SD) age of $48.7 \pm$ 10.5 years. Of the total subjects, 294 (23.9\%) had hyperuricemia, with a preponderance of men (58.5\%) as compared to women (41.5\%). On analysis within gender, $27.3 \%$ of men and $20.4 \%$ of women had hyperuricemia, and in comparison to those with normouricemia, the hyperuricemia group tended to be heavier (with increased body weight, BMI and WC) and to have increased TG levels and higher diastolic BP. On the other hand, levels of TC, LDL-C, HDL-C, glucose and systolic BP did not differ significantly between the two groups.

The adjusted and unadjusted odds ratios for the putative determinants of uric acid status (hyperuricemia vs. normouricemia) for the subjects are shown in table 2. Adjustments were made for age, gender, BMI and diabetes status whenever the $\mathrm{p}$ values were significant. In these analyses, the age grouping was collapsed into two categories according to the National Cholesterol Education Program ATP III criteria for the definition of premature ischemic heart disease, i.e. men aged $\leq 45$ years and women aged $\leq 55$ years [16]. Serum uric acid levels were higher in males than in females when further compared by covariance analysis to correct for potential confounding from age, diabetes status and BMI. It was additionally noted that, in the hyperuricemia group, 168 (57\%), 106 (36\%) and 77 (26\%) were obese, smoked regularly and/or had diagnosed diabetes, respectively. Furthermore, hypertension was present in 137 (47\%) of the hyperuricemic patients in whom 113 (38\%) had low HDL and $235(80 \%)$ were hypertriglyceridemic. After adjusting for possible covariates, as shown in table 2, gender, BMI and diabetes emerged as the independent determinants of uric acid status in all the subjects considered as a whole.

The relationship between the various components of MetS and uric acid status was gender specific (table 3). In the men, since older age was associated with greater WC and presence of impaired fasting glucose (IFG) and hypertension, we adjusted for age and observed that the serum uric acid level was higher in those with MetS, large WC, IFG and hypertension. In women however, after adjusting for age, a large WC was the only significant association with the serum uric acid level. In neither gender did dyslipidemia (low HDL, high TG) contribute significantly to uric acid levels.

These disparate observations for men and women were further explored in table 4, which specifically assessed the individual effects of WC, IFG and hyperten- 
Table 2. Odds ratios (OR) of hyperuricemia for potential determinants of uric acid status for all subjects

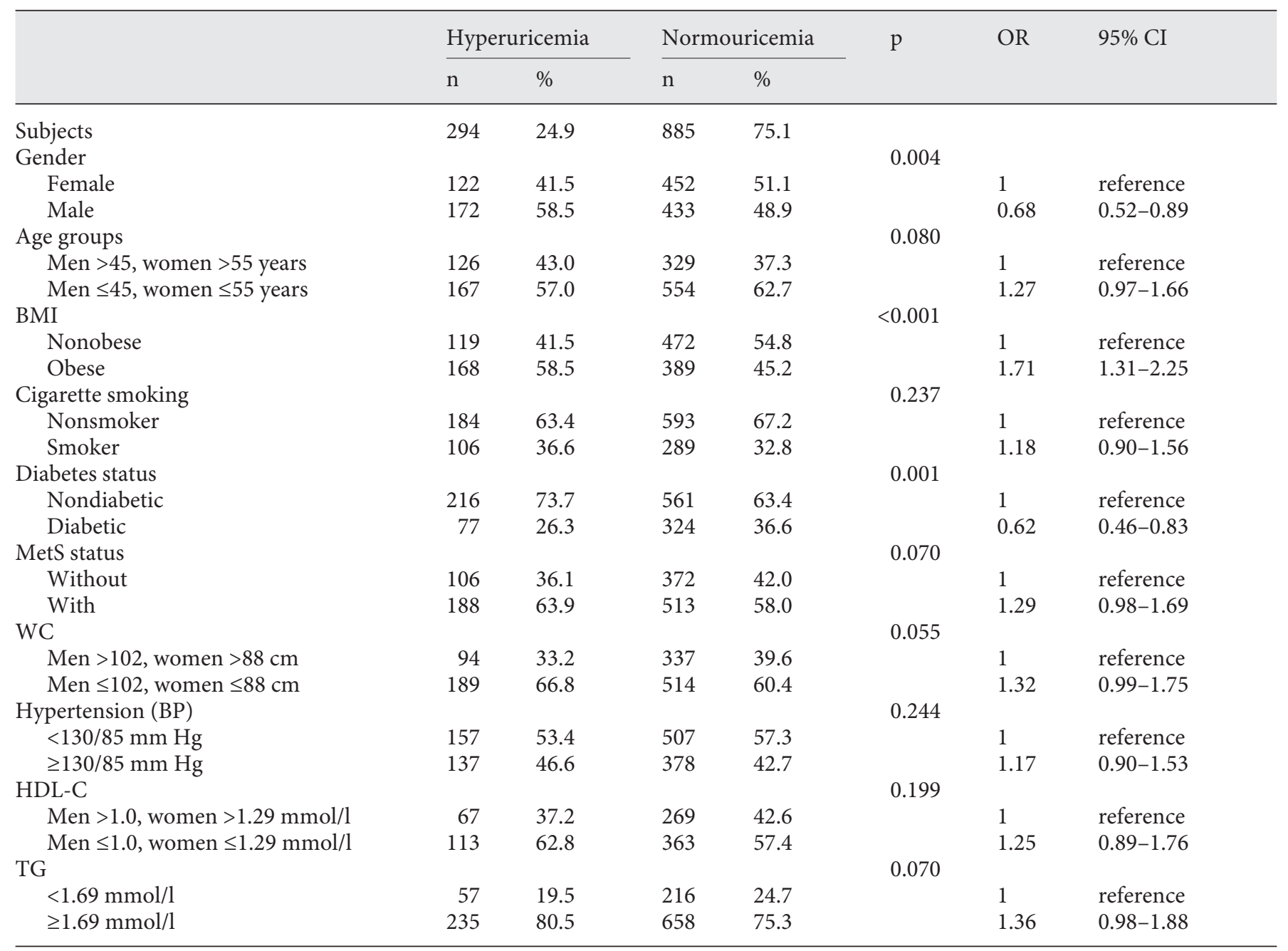

Gender: after adjustment for age, diabetes and BMI. BMI: after adjustment for age, gender and diabetes. Diabetes: after adjustment for age, BMI and gender.

sion in men and women. Different groups were identified according to number of MetS components as follows: $\mathrm{A}=$ without large WC, dyslipidemia, IFG and/or high BP; B = with large WC but without dyslipidemia, IFG and/or high $\mathrm{BP} ; \mathrm{C}=$ with large WC and dyslipidemia but without IFG and/or high BP; D = with large WC, dyslipidemia, IFG and/or high BP. The analyses revealed significant groupbased differences for both men and women; in men, group D serum uric acid was significantly higher than in group C, and group B had nonstatistically significant higher levels than group A; for the women, group D subjects had higher uric acid levels than those in group B.
The changes in serum uric acid and lipid and lipoprotein levels with specific treatment (statins, typically atorvastatin, for predominant hypercholesterolemia and fibrates, typically gemfibrozil or bezafibrate, for predominant hypertriglyceridemia) in the subjects at baseline and on follow-up at the Lipid Clinic at 4-6 months and 12-14 months are presented in table 5. Of the 468 subjects on fibrates, 443 (95\%) were on bezafibrate and 23 (5\%) on gemfibrozil, mainly because the former is available free of charge to all. Only $2(0.4 \%)$ of the subjects were on fenofibrate as it was not regularly freely available. The data were essentially similar for gemfibrozil and bezafibrate, 
Table 3. Gender-based differential relationships of MetS and its components with hyperuricemia in dyslipidemic subjects

\begin{tabular}{|c|c|c|c|c|}
\hline & Age, years & Uric acid, $\mu \mathrm{mol} / \mathrm{l}$ & $\mathrm{p}$ & $\mathrm{p}$ adjusted \\
\hline \multicolumn{5}{|l|}{ Men } \\
\hline MetS & & & 0.025 & 0.033 \\
\hline Present $(\mathrm{n}=353)$ & $45.5 \pm 9.6$ & $377.0 \pm 98.0$ & & \\
\hline Absent $(\mathrm{n}=297)$ & $43.8 \pm 11.3$ & $361.6 \pm 83.1$ & & \\
\hline WC & & & 0.025 & 0.029 \\
\hline$\geq 102 \mathrm{~cm}(\mathrm{n}=263)$ & $46.1 \pm 9.9$ & $379.2 \pm 94.7$ & & \\
\hline$<102 \mathrm{~cm}(\mathrm{n}=341)$ & $43.7 \pm 10.6$ & $363.4 \pm 89.5$ & & \\
\hline Fasting glucose & & & 0.013 & 0.006 \\
\hline$\geq 6.1 \mathrm{mmol} / \mathrm{l}(\mathrm{n}=252)$ & $47.3 \pm 9.9$ & $378.1 \pm 85.7$ & & \\
\hline$<6.1 \mathrm{mmol} / \mathrm{l}(\mathrm{n}=377)$ & $43.0 \pm 10.4$ & $357.8 \pm 100.4$ & & \\
\hline $\mathrm{BP}$ & & & 0.009 & 0.012 \\
\hline$\geq 130 / 85 \mathrm{~mm} \mathrm{Hg}(\mathrm{n}=274)$ & $46.7 \pm 9.3$ & $380.2 \pm 90.9$ & & \\
\hline$<130 / 85 \mathrm{~mm} \mathrm{Hg}(\mathrm{n}=359)$ & $43.2 \pm 11.0$ & $362.4 \pm 92.4$ & & \\
\hline \multicolumn{5}{|l|}{ Dyslipidemia } \\
\hline With $(\mathrm{n}=498)$ & $43.9 \pm 9.7$ & $372.3 \pm 94.2$ & 0.214 & 0.176 \\
\hline Without $(\mathrm{n}=121)$ & $48.5 \pm 12.4$ & $362.2 \pm 82.6$ & & \\
\hline \multicolumn{5}{|l|}{ Women } \\
\hline MetS & & & 0.139 & 0.407 \\
\hline Present $(n=373)$ & $50.3 \pm 9.0$ & $301.6 \pm 78.0$ & & \\
\hline Absent $(\mathrm{n}=224)$ & $45.2 \pm 12.1$ & $294.6 \pm 69.6$ & & \\
\hline WC & & & $<0.001$ & 0.001 \\
\hline$\geq 88 \mathrm{~cm}(\mathrm{n}=465)$ & $51.3 \pm 8.6$ & $305.2 \pm 75.9$ & & \\
\hline$<88 \mathrm{~cm}(\mathrm{n}=110)$ & $46.1 \pm 11.3$ & $273.2 \pm 66.0$ & & \\
\hline Fasting glucose & & & 0.705 & 0.727 \\
\hline$\geq 6.1 \mathrm{mmol} / \mathrm{l}(\mathrm{n}=280)$ & $49.9 \pm 9.4$ & $299.9 \pm 82.2$ & & \\
\hline$<6.1 \mathrm{mmol} / \mathrm{l}(\mathrm{n}=315)$ & $42.6 \pm 12.6$ & $298.4 \pm 68.5$ & & \\
\hline BP & & & 0.073 & 0.202 \\
\hline$\geq 130 / 85 \mathrm{~mm} \mathrm{Hg}(\mathrm{n}=260)$ & $50.6 \pm 8.6$ & $305.0 \pm 81.3$ & & \\
\hline$<130 / 85 \mathrm{~mm} \mathrm{Hg}(\mathrm{n}=337)$ & $46.9 \pm 11.5$ & $294.5 \pm 69.8$ & & \\
\hline Dyslipidemia & & & 0.100 & 0.066 \\
\hline With $(\mathrm{n}=481)$ & $48.4 \pm 10.2$ & $300.7 \pm 75.9$ & & \\
\hline Without $(\mathrm{n}=116)$ & $49.3 \pm 11.6$ & $291.0 \pm 71.4$ & & \\
\hline
\end{tabular}

Data are expressed as means \pm SD; p adjusted indicates p values adjusted for age; dyslipidemia: includes low HDL and/or high TG levels.

and so both were pooled for further statistical analyses. With statin treatment, mean baseline uric acid levels significantly decreased by $5.8 \%(\mathrm{p}<0.001)$ in $4-6$ months and up to $9.0 \%$ at the end of the first year of treatment. This was accompanied by the expected major decreases in TC, LDL levels and a trivial reduction in TG levels. On the other hand, serum uric acid levels appeared to increase (albeit nonsignificantly) during the same followup duration in the patients administered fibrates, in spite of the expected major falls in TC and TG levels with a modest increase in HDL-C.

Determinants of Urate Levels in Dyslipidemia

\section{Discussion}

In this study, we have attempted to evaluate the associations of uric acid levels with a wide variety of clinical, anthropometric and biochemical parameters in a large group of dyslipidemic patients being followed up at a major teaching hospital in Kuwait. Dyslipidemia is itself a major CAD risk factor in Kuwait and the Arabian Gulf Region [17, 18], as elsewhere [19], and therefore our objective was to assess if the urate changes were merely incidental on the lifestyle issues resulting in dyslipidemia (such as obesity, high fat diets and poor physical activity) 
Table 4. Serum uric acid levels based on numbers of MetS components

\begin{tabular}{ccclrll}
\hline & WC & $\begin{array}{l}\text { Dyslip- } \\
\text { idemia }\end{array}$ & $\begin{array}{l}\text { IFG } \pm \\
\text { high BP }\end{array}$ & & \multicolumn{1}{l}{$\begin{array}{l}\text { Uric acid, } \\
\mu \mathrm{mol} / 1\end{array}$} & $\mathrm{p}$ \\
\hline Men & & & & & & 0.045 \\
Group A & - & - & - & 32 & $364.5 \pm 76.2$ & \\
Group B & + & - & - & 161 & $370.0 \pm 85.4$ & \\
Group C & + & + & - & 239 & $360.1 \pm 92.0$ & \\
Group D & + & + & + & 160 & $387.0 \pm 99.9$ & \\
Women & & & & & & 0.026 \\
Group A & - & - & - & 16 & $276.1 \pm 84.5$ & \\
Group B & + & - & - & 75 & $277.4 \pm 59.5$ & \\
Group C & + & + & - & 186 & $299.9 \pm 71.3$ & \\
Group D & + & + & + & 287 & $305.2 \pm 79.6$ & \\
All subjects & & & & & & 0.791 \\
Group A & - & - & - & 48 & $336.3 \pm 88.5$ & \\
Group B & + & - & - & 236 & $340.8 \pm 89.1$ & \\
Group C & + & + & - & 425 & $333.4 \pm 88.5$ & \\
Group D & + & + & + & 447 & $334.4 \pm 95.7$ & \\
\hline
\end{tabular}

Uric acid results are expressed as means $\pm \mathrm{SD} ; \mathrm{n}=$ number of subjects; $p$ values derived from one-way analysis of variance. Group A: without large WC, dyslipidemia, IFG and/or high BP. Group B: with large WC but without dyslipidemia, IFG and/or high BP. Group C: with large WC and dyslipidemia but without IFG and/or high BP. Group D: with large WC, dyslipidemia, IFG and/or high BP. or could indeed be additive to the risk posed directly by dyslipidemia.

The study indicated that $24 \%$ of the dyslipidemic patients had hyperuricemia, with proportionally more men (28\%) than women $(20 \%)$ affected. These rates are $2-4$ times higher than those described for the general 'healthy' Arab [5] or Caucasian populations [3, 4]. Gender (male sex), obesity (as assessed with BMI) and diabetes were significant determinants of whether or not an individual would have hyperuricemia, even after adjustment for potential confounding. Of interest is the further finding that, in the whole group of subjects, important CAD risk variables such as age, MetS, large WC, atherogenic dyslipidemia (low HDL and high TG levels), cigarette smoking and high BP did not influence per se whether or not an individual would have hyperuricemia. However, these findings were gender specific - the associations of high uric acid levels in men (presence of MetS, large WC, fasting hyperglycemia and hypertension) were more robust than in women (only large WC), even after adjustment for confounding.

This finding of a relationship between hyperuricemia and MetS (with some of its main components) is probably due to the unifying underlying pathogenetic mechanism of insulin resistance, which with its associated hyperin-

Table 5. Serum uric acid and lipid levels at diagnosis (baseline) and on follow-up at 4-6 and 12-14 months in subjects with specific treatment

\begin{tabular}{|c|c|c|c|c|}
\hline & Baseline & 4-6 months & 12-14 months & $\mathrm{p}$ value \\
\hline \multicolumn{5}{|l|}{ Statins } \\
\hline Uric acid, $\mu \mathrm{mol} / \mathrm{l}$ & $344.6 \pm 104.6$ & $324.3 \pm 78.9$ & $313.1 \pm 79.1$ & $<0.001$ \\
\hline $\mathrm{TC}, \mathrm{mmol} / \mathrm{l}$ & $8.0 \pm 2.2$ & $6.8 \pm 1.9$ & $6.3 \pm 1.8$ & $<0.001$ \\
\hline LDL-C, mmol/l & $6.3 \pm 3.6$ & $4.9 \pm 2.4$ & $4.3 \pm 1.9$ & $<0.001$ \\
\hline HDL-C, mmol/l & $1.14 \pm 0.38$ & $1.14 \pm 0.31$ & $1.14 \pm 0.30$ & 0.993 \\
\hline $\mathrm{TG}, \mathrm{mmol} / \mathrm{l}$ & $2.8 \pm 2.8$ & $2.3 \pm 1.8$ & $2.4 \pm 2.7$ & 0.010 \\
\hline \multicolumn{5}{|l|}{ Fibrates } \\
\hline Uric acid, $\mu \mathrm{mol} / \mathrm{l}$ & $337.4 \pm 76.1$ & $346.4 \pm 77.9$ & $341.1 \pm 86.0$ & 0.502 \\
\hline $\mathrm{TC}, \mathrm{mmol} / \mathrm{l}$ & $8.1 \pm 2.6$ & $6.5 \pm 1.4$ & $6.4 \pm 1.7$ & $<0.001$ \\
\hline LDL-C, mmol/l & $4.7 \pm 0.9$ & $4.4 \pm 0.9$ & $4.0 \pm 1.3$ & 0.141 \\
\hline HDL-C, mmol/l & $1.02 \pm 0.31$ & $1.08 \pm 0.27$ & $1.01 \pm 0.26$ & 0.058 \\
\hline $\mathrm{TG}, \mathrm{mmol} / \mathrm{l}$ & $10.1 \pm 9.9$ & $5.0 \pm 6.8$ & $5.3 \pm 6.2$ & $<0.001$ \\
\hline
\end{tabular}

Results are expressed as means $\pm \mathrm{SD}$. Analyses were performed by one-way repeated-measures analysis of variance with Bonferroni's correction for multiple comparisons. 
sulinemia increases circulating uric acid levels possibly through one or more of: enhanced insulin action with decreased renal excretion of uric acid and increased whole-body uric acid production [20]; enhanced activity of the hexose monophosphate shunt with increased purine biosynthesis and turnover [21]; presence of hypertension and possibly decreased renal blood flow and microischemia, increased renal lactate secretion, and reduced renal uric acid excretion [22]. Furthermore, hyperuricemia could, in turn, worsen insulin resistance via effects on endothelial NO $[22,23]$ and potentially create a vicious cycle.

The gender-related differences in blood levels and associations of uric acid observed in this study confirmed observations elsewhere [23] and are most likely due to the hormonal (estrogen and testosterone) differences between men and women [24], with the increase in male muscle and skeletal mass and the consequent increased supply of purines.

Our results further showed that statin (but not fibrate) treatment of dyslipidemia resulted in reduction in serum uric acid levels without additional use of uricolytic or uricosuric drugs. This observation is likely to be statin specific and not due to the attendant lifestyle change advice, which was freely and generally offered to all patients, irrespective of the type of drug treatment. Similarly, it is unlikely to be due to poor compliance to therapy by patients on fibrates, since they demonstrated effectiveness of treatment with significant reductions in levels of TG and TC. Indeed, uric acid levels even tended to rise slightly with treatment using fibrates (gemfibrozil or bezafibrate), by $2.6 \%$ at $4-6$ months and $1.1 \%$ at 12-14 months. However, a previous study [25] reported that serum uric acid levels decreased by almost $28 \%$ with fenofibrate treatment - with the implication that the effects of this group of drugs on uric acid levels might be specifically drug-dependent. In any case, the clear results in relation to statins, which has also been reported in other populations $[11,12]$, reinforce the conviction that statin effects are pleiotropic in improving endothelial function and overall vascular health, in addition to significantly reducing circulating lipid levels $[26,27]$. The other drugs that have been described to potentially affect serum uric acid levels in our patients are antihypertensives (such as thiazide diuretics and losar$\tan )$ and nonsteroidal anti-inflammatory drugs [25, 28]. However, the subjects in the study primarily taking either statins or fibrates had an equal likelihood of having hypertension (and being on a thiazide diuretic, with none under losartan treatment) or taking nonsteroidal anti-inflammatory drugs, so these could not have influenced our observations.

The major strength of this study was its large number of a socioculturally homogeneous population followed up in a teaching hospital environment in a country with essentially free health care and no poverty-related issues in drug compliance. However, there were some limitations to the study, in that patients were not strictly regarding clinic attendance. We did not have a control nondyslipidemic population either, because the objective was to investigate a population already at high CAD risk. Furthermore, we did not assess alcohol intake for legal and religious reasons.

\section{Conclusion}

This study showed that: (i) about a quarter of dyslipidemic subjects attending the Lipid Clinic in Kuwait had hyperuricemia; (ii) the associations of hyperuricemia were gender specific, variably including different components of MetS; (iii) atherogenic dyslipidemia (low HDL, high TG), per se, was not associated with hyperuricemia; (iv) circulating uric acid levels were reduced by about $9 \%$ over a 1-year time period with statin (but not fibrate) treatment.

\section{Acknowledgements}

We are grateful to the physicians and nurses in the Lipid Clinic, Mubarak Al-Kabeer Hospital, Kuwait, for granting us access to the clinic database. We also thank Prof. T.A. Junaid, Chairman, Department of Pathology, and Mr. Jasem Al-Khorafi, Administration Manager, HSC, Kuwait University, for granting us permission to use Department of Pathology facilities after regular duty hours and Ms. Reema Mathew, Department of Pathology, for her technical support.

References

1 Villegas R, Xiang YB, Cai Q, Fazio S, Linton M, Li H, Elasy T, Zheng W, Shu XO: Prevalence and determinants of hyperuricemia in middle-aged, urban Chinese men. Metab Syndr Relat Disord 2010;8:263-270.

$\checkmark 2$ Lohsoonthorn V, Dhanamun B, Williams MA: Prevalence of hyperuricemia and its relationship with metabolic syndrome in Thai adults receiving annual health exams. Arch Med Res 2006;37:883-889.

3 Sturge RA, Scott JT, Kennedy AC, Hart DP, Buchanan WW: Serum uric acid in England and Scotland. Ann Rheum Dis 1977;36:420 427. 
4 Schmidt MI, Watson RL, Duncan BB, Metcalf P, Brancati FL, Sharrett AR, Davis CE, Heiss G: Clustering of dyslipidemia, hyperuricemia, diabetes, and hypertension and its association with fasting insulin and central and overall obesity in a general population. Atherosclerosis Risk in Communities Study Investigators. Metabolism 1996;45:699-706.

5 Al-Arfaj A: Hyperuricemia in Saudi Arabia. Rheumatol Int 2001;20:61-64.

6 Nagahama K, Iseki K, Inoue T, Touma T, Ikemiya Y, Takishita S: Hyperuricemia and cardiovascular risk factor clustering in a screened cohort in Okinawa, Japan. Hypertens Res 2004;27:227-233.

7 Al-Isa A, Akanji AO, Thalib L: Prevalence of the metabolic syndrome among female $\mathrm{Ku}$ waiti adolescents using two different criteria. Br J Nutr 2009;7:1-5.

8 Sanisoglu SY, Oktenli C, Hasimi A, Yokusoglu M, Ugurlu M: Prevalence of metabolic syndrome-related disorders in a large adult population in Turkey. BMC Public Health 2006;6:92.

-9 Ford ES, Giles WH, Dietz WH: Prevalence of the metabolic syndrome among US adults: findings from the third National Health and Nutrition Examination Survey. JAMA 2002; 287:356-359.

10 Liou TL, Lin MW, Hsiao LC, Tsai TT, Chan WL, Ho LT, Hwu CM: Is hyperuricemia another facet of the metabolic syndrome? J Chin Med Assoc 2006;69:104-109.

-11 Ogata N, Fujimori S, Oka Y, Kaneko K: Effects of three strong statins (atorvastatin, pitavastatin, and rosuvastatin) on serum uric acid levels in dyslipidemic patients. Nucleosides Nucleotides Nucleic Acids 2010;29: 321-324.
12 Athyros VG, Elisaf M, Papageorgiou AA, Symeonidis AN, Pehlivanidis AN, Bouloukos VI, Milionis HJ, Mikhailidis DP; GREACE Study Collaborative Group: Effect of statins versus untreated dyslipidemia on serum uric acid levels in patients with coronary heart disease: a subgroup analysis of the GREek Atorvastatin and Coronary-heartdisease Evaluation (GREACE) study. Am J Kidney Dis 2004;43:589-599.

13 Al-Huthi MA, Raja’a YA, Al-Noami M, Abdul Rahman A: Prevalence of coronary risk factors, clinical presentation, and complications in acute coronary syndrome patients living at high vs low altitudes in Yemen. MedGenMed 2006;8:28.

14 Qadan LR, Ahmed AA, Safar HA, Al-Bader MA, Ali AA: Prevalence of metabolic syndrome in patients with clinically advanced peripheral vascular disease. Angiology 2008; 59:198-202.

15 Warnick GR, Knopp RH, Fitzpatrick V, Branson L: Estimating low-density lipoprotein cholesterol by the Friedewald equation is adequate for classifying patients on the basis of nationally recommended cutpoints. Clin Chem 1990;36:15-19.

16 Expert Panel on Detection, Evaluation and Treatment of High Blood Cholesterol in Adults: Executive summary of the third report of the National Cholesterol Education Program (NCEP) expert panel on detection, evaluation, and treatment of high blood cholesterol in adults (Adult Treatment Panel III). JAMA 2001;285:2486-2497.

17 Akanji AO: Diabetic dyslipidaemia in Kuwait. Med Princ Pract 2002;11(suppl 2):4755.

18 Abdulle AM, Nagelkerke N, Abouchacra S, Obineche EN: Potential benefits of controlling coronary heart disease risk factors in the United Arab Emirates. Kidney Blood Press Res 2008;31:185-188.

-19 Meagher EA: Addressing cardiovascular disease in women: focus on dyslipidemia. J Am Board Fam Pract 2004;17:424-437.
20 Tsouli SG, Liberopoulos EN, Mikhailidis DP, Athyros VG, Elisaf MS: Elevated serum uric acid levels in metabolic syndrome: an active component or an innocent bystander? Metabolism 2006;55:1293-1301.

-21 Lippi G, Montagnana M, Franchini M, Favaloro EJ, Targher G: The paradoxical relationship between serum uric acid and cardiovascular disease. Clin Chim Acta 2008; 392:1-7.

22 Numata T, Miyatake N, Wada J, Makino H: Comparison of serum uric acid levels between Japanese with and without metabolic syndrome. Diabetes Res Clin Pract 2008; 80:e1-e5.

23 Hayden M, Tyagi S: Uric acid: a new look at an old risk marker for cardiovascular disease, metabolic syndrome, and type 2 diabetes mellitus - the urate redox shuttle. Nutr Metab (Lond) 2004;1:10.

24 Sumino H, Ichikawa S, Kanda T, Nakamura T, Sakamaki T: Reduction of serum uric acid by hormone replacement therapy in postmenopausal women with hyperuricaemia. Lancet 1999;354:650.

25 Daskalopoulou SS, Tzovaras V, Mikhailidis DP, Elisaf M: Effect on serum uric acid levels of drugs prescribed for indications other than treating hyperuricaemia. Curr Pharm Des 2005; 11:4161-4175.

26 Bonetti PO, Lerman LO, Napoli C, Lerman A: Statin effects beyond lipid lowering - are they clinically relevant? Eur Heart J 2003;24: 225-248.

-27 Mcfarlane SI, Muniyappa R, Francisco R, Sowers JR: Pleiotropic effects of statins: lipid reduction and beyond. J Clin Endocrinol Metab 2002;87:1451-1458.

28 Malik J, Melenovsky V, Wichterle D, Haas T, Simek J, Ceska R, Hradec J: Both fenofibrate and atorvastatin improve vascular reactivity in combined hyperlipidaemia (fenofibrate versus atorvastatin trial - FAT). Cardiovasc Res 2001;52:290-298. 